\title{
ASSISTÊNCIA MULTIPROFISSIONAL NA REABILITAÇÃO DA COMUNICAÇÃO DA PESSOA LARINGECTOMIZADA*
}

\author{
MULTIPROFESSIONAL ASSISTANCE FOR REHABILITATION OF \\ LARYNGECTOMEES COMMUNICATION HABILITY
}

Marcia Maria Fontão Zago**

Namie Okino Sawada***

ZAGO, M.M.F. Assistência multiprofissional na rea bilitação da comunicação da pessoa laringectomizada. Rev.Esc.Enf.USP, v.32, n. 1, p. 67.72, abr. 1998.

\section{RESUMO}

Este artigo tem como objetivo divulgar a experiência de um grupo de profissionais envolvidos na reabilitação e na reabilitação vocal dos laringectomizados que participam do GARPO-Laringectomizados. São descritas as diferentes possibilidades de reabilitação vocal para o laringectomizado como também, os pressupostos que permeiam todas as atividades e etapas do processo. Destaca-se as características da pessoas laringectomizadas, as conseqüências da cirurgia, o significado de ser laringectomizado que direcionam a assistência do enfermeiro no processo, em integração com o fonoaudiólogo.

UNITERMOS: Reabilitação. Reabilitação vocal. Laringectomizado.

\section{ABSTRACT}

The purpose of this study was to bring basic information about the work of a multiprofissional group involved with the laryngectomees rehabilitation and vocal rehabilitation. Those patients take part in the GARPO-Laryngectomees. The authors describe the different possibilities of vocal rehabilitation for the patients and the framework of the activities and steps of the process. They emphasize the laryngectomees characteristics, the surgical results, and the meaning of being a laryngectomee, as the basis to direct the nurses and the speech therapeutists assistance.

UNITERMS : Rehabilitation. Vocal rehabilitation. Laryngectomee.

\section{INTRODUÇÃO}

Até o início da década de 90 , eram poucos os enfermeiros que atuavam com os pacientes da especialidade de Cabeça e Pescoço. Atualmente, temos observado nos eventos da enfermagem relatos e estudos envolvendo esses pacientes. Por outro lado, por estarmos envolvidas nessa área, sabemos que a literatura de enfermagem é escassa em informações sobre a assistência e a reabilitação desses pacientes.

Dentro da especialidade de Cabeça e Pescoço, o grupo de pacientes submetidos à laringectomia total é o que mais nos preocupa visto a mutilação a que sofrem.
O GARPO-Laringectomizados (Grupo de Apoio e Reabilitação de Pessoas Ostomizadas . Laringectomizados) foi formado em 1990 e integra profissionais da Escola de Enfermagem de Ribeirão Preto-USP e Hospital das Clínicas da Faculdade de Medicina de Ribeirão Preto-USP. Os objetivos do grupo visam a assistência, o ensino e a pesquisa sobre a reabilitação das pessoas laringectomizadas. Para o alcance desses objetivos, o eixo integrador das atividades realizadas é o ensino de pacientes.

Os pacientes que participam do grupo são provenientes do Serviço de Cirurgia de Cabeça e

\footnotetext{
* Palestra apresentada no $4^{\circ}$ Simpósio Brasileiro de Comunicação em Enfermagem (SIBRACEn), realizado emRibeirão Preto-SP

* Enfermeira. Professora Doutora da Escola de Enfermagem de Ribeirão Preto-USP, Coordenadora do GARPO-Laringectomizados.

*** Enfermeira. Professora Doutora da Escola de Enfermagem de Ribeirão Preto-USP, Participante do GARPO-Laringectomizados.
} 
Pescoço e Endoscopia Per-Oral, da instituição antes referida.

Desde o início das suas atividades, o GARPO Laringectomizados tem expandido a sua atuação em relação à assistência prestada aos pacientes e familiares, como também, em relação ao envolvimento de profissionais de outras áreas.

Conscientes de que a reabilitação vocal da pessoa laringectomizada é um dos pontos fundamentais para a sua reabilitação, procuramos reunir neste artigo, os pressupostos e aspectos que podem direcionar o trabalho futuro de outros profissionais.

\section{O PACIENTE COM CÂNCER DE LARINGE}

Segundo KOWALSKI ${ }^{5}$, o câncer de laringe tem tido a sua incidência aumentada nos últimos anos, principalmente no Estado de São Paulo. Para o autor, há estimativas de que no estado devam ter ocorrido cerca de 2200 novos casos de câncer de laringe, entre 1990 e 1995 . A maioria de casos é diagnosticada em fases avançadas de evolução.

O consumo de tabaco e de bebidas alcoblicas é o principal fator de risco para a doença. Há um efeito dose-resposta e sinergístico para esses fatores. Exposições ocupacionais às fibras têxteis, níquel, pó de madeira e asbestos e os hábitos precários de higiene oral também são fatores de risco. Não há predominância racial e o câncer de laringe é considerado de grande prevalência nos centros urbanos. $\mathrm{O}$ câncer de laringe compreende cerca de $6 \%$ de todos os tumores malignos que ocorrem na população de sexo masculino, acometendo indivíduos de faixa etária economicamente ativa ${ }^{1,5}$.

Resumidamente, as características predominantes dos pacientes com câncer de laringe em nosso meio são:

- sexo: 5 homens/1 mulher

- idade: acima 50 anos

- etiologia: alcoolismo e tabagismo

- baixo nível sócio-econômico-educacional

- rede de apoio familiar enfraquecida

- tumor em fase avançada

\section{O TRATAMENTO CIRÚRGICO}

As pessoas com câncer de laringe, em estágios III e IV, submetem-se ao procedimento cirúrgico denominado "laringectomia total". A cirurgia tem como objetivo a remoção de tumor. Em geral, é associado a ressecção cervical ganglionar para assegurar a extirpação total do tumor. No pós- operatório, a radioterapia complementa o tratamento ${ }^{8,12}$.

A curabilidade do câncer, bem como a qualidade de sobrevida, têm aumentado substancialmente segundo a localização e histologia de tumor, após a cirurgia. Atualmente, cerca de 50 a $60 \%$ dos casos sobrevivem mais de cinco anos. Entretanto, a recorrência acontece em $40 \%$ dos pacientes; $80 \%$ são locais ou regionais e $20 \%$ com metástase à distância ${ }^{15,6}$.

$\mathrm{Na}$ laringectomia total são removidas as estruturas que produzem o som laríngeo, ou seja, o esqueleto cartilaginoso da laringe (as pregas ou cordas vocais) e vários músculos vizinhos. A parte superior da faringe é suturada à base da língua e a traquéia suturada à pele da base do pescoço, onde é realizada uma abertura, chamada traqueostoma, para a respiração. Depois da cirurgia, o indivíduo perde a capacidade de emissão do som laríngeo (afonia) $^{5, ?}$

Na literatura cirúrgica, há um consenso em considerar este procedimento como altamente mutilatorio, devido as conseqüencias para o paciente ${ }^{12,5,3}$ que podem ser diferenciadas em:

a) fisiológicas:

- alteração da via respiratória

- traqueostomia permanente

- afonia

- diminuição da atividade motora do ombro, braço e pescoço

- diminuição do olfato e paladar

b) psicossociais:

- alteração da imagem corporal

- alteração da comunicação

- alteração das atividades sociais

- alteração da auto-estima

Essas conseqüências, ou alterações, podem ser amenizadas através de diferentes recursos, porém, dificilmente a pessoa conseguirá recuperar as suas percepções anteriores de normalidade.

\section{ASSISTÊNCIA À REABILITAÇÃO DA COMUNICAÇÃO DA PESSOA LARINGECTOMIZADA}

Para os profissionais do GARPOLaringectomizados a assistência para a reabilitação fundamenta-se nos seguintes pressupostos:

- todo indivíduo tem capacidade para desenvolver o autocuidado e participar ativamente da sua reabilitação, independente do seu nível sócioeconômico-educacional; 
- aos profissionais cabe facilitar o desenvolvimento das capacidades do indivíduo, através da atividade educativa e do apoio;

- a reabilitação é um processo de ensinoaprendizagem mútuo entre pacientes e profissionais.

ZAGO; STOPA; MARTINEZ ${ }^{13}$, com a finalidade de apreenderem a percepção que os pacientes têm de si mesmos, identificaram o significado cultural de "ser laringectomizado". O significado pode ser compreendido por quatro categorias temáticas: ser diferente, ser dependente, ter baixa auto-estima e ter esperança.

Essas categorias expõem as dificuldades e expectativas dos pacientes, que surgem ciclicamente durante a reabilitação. A imagem corporal alterada e a afonia são dois componentes que se integram e geram a baixa auto-estima e o isolamento social que eles impõem a si mesmos. A percepção da incapacidade fisiológica em utilizar a voz para comunicar-se, altera o estado psicológico e, consequentemente, afeta as atividades sociais. As conseqüências da cirurgia fazem com que os pacientes sintam-se como pessoas oprimidas devido aos valores culturais e sociais que determinam a valorização da voz, como o principal meio de comunicação, e a beleza, como valor estético.

Por outro lado, a reabilitação vocal gera a expectativa de melhora da sua condição, indispensável para reassumir a sua função social. STEFFEN ${ }^{11}$ destaca que a capacidade de raciocínio e a exteriorização do pensamento através da voz, são as duas grandes propriedades que possui o ser humano. Portanto, a voz é um componente essencial para uma integração harmônica no convívio social. A perda da voz pela laringectomia representa ao ser humano não somente a agressão ao órgão fonatório, mas, a invasão e destruição de seu esquema de integridade e de integração biopsicossocial. Assim, não podemos tratar a reabilitação vocal isoladamente. É necessário que a projetemos num contexto mais amplo de reabilitação psicológica, social, profissional, estética e funcional.

Existem várias possibilidades com as quais as pessoas laringectomizadas podem recuperar a voz, favorecendo a comunicação verbal-oral:

\section{A- Reabilitação Cirúrgica da Voz}

A reconstrução cirúrgica da voz, ou neocorda vocal, consiste na confecção de um tubo de pele que conecta a traquéia a uma fístula faríngea, produzindo um mecanismo vibratório que origina uma voz modulada. Quando o paciente oblitera o traqueostoma, com o dedo, o ar expirado passa através desse tubo de pele para a faringe e à boca, possibilitando a fonação. São contra-indicações para o procedimento: a radioterapia $\mathbf{e}$ a recidiva do câncer.
Embora a recuperação da voz seja imediata, a sua desvantagem está em acarretar a aspiração pulmonar da saliva e alimentos pelo faringostoma.

Outro método consiste na confecção de uma fístula traqueo-faríngea, onde será inserida a prótese de Bloom-Singer. A utilização da prótese é certamente a mais fácil e a mais rápida forma de reabilitação vocal após laringectomia total. Uma vez inserida, o paciente tem condições de emitir a voz. A principal desvantagem deve-se à dependência do paciente à prótese. Nem todos os pacientes conseguem mantê-la, seja pela falta de habilidade em retirá-la, conservá-la limpa ou mesmo recolocála.

A prótese tem vida útil de mais ou menos três meses, ficando o paciente na dependência de sempre ter consigo uma prótese sobressalente. Por ser um material importado, é de custo elevado7.

No serviço em que atuamos, a reabilitação cirúrgica da voz não é realizada.

\section{B- A eletrolaringe ou laringe eletrônica}

A eletrolaringe é um amplificador movido a bateria ou pilha que emite uma onda sonora contínua. Esta vibração sonora é transmitida ao ressonador buconasofaríngeo e esta pseudovoz é transformada em forma de palavra falada pelos orgãos articuladores, lábios, língua e dentes.. A laringe eletrônica utilizada mais freqüentemente é a justacervical, que o paciente pressiona na região submandibular ou na porção mediana do pescoço.

$\mathrm{O}$ uso da laringe eletrônica apresenta alguns aspectos negativos quando comparado com a voz esofágica:

- requer o uso das mãos,

- produz um som contínuo e irritante,

- sendo um instrumento, está sujeito a defeitos de funcionamento,

- a qualidade da voz é monótona, antinatural, sem inflexões (voz de robô),

- chama a atenção das pessoas para a deficiência

física,

- custo elevado.

Embora haja desvantagens, todo laringectomizado deve ter acesso à demonstração $\mathrm{e}$ possibilidade para experimentá-la. Cabe ao paciente optar pelo recurso que acha de melhor qualidade e que se adequa às suas características ${ }^{7,2}$.

Para os pacientes do serviço, a laringe eletrônica é indicada quando, por problemas de ordem física ou emocional, os laringectomizados não conseguem produzir a voz esofágica.

\section{C- Voz esofágica ou erigmofonação}

Segundo BEHLAU; ZIEMER² e OLIVEIRA; 
OLIVEIRA ${ }^{2}$, o elemento motriz da voz esofágica é o ar deglutido e armazenado no esôfago. O som produzido é lançado à hipofaringe, orofaringe e rinofaringe, que servirão como caixa de ressonância. A vocalização é feita, como sempre, pela língua, lábios, palato e dentes. O método consiste de várias etapas: 1- independência da fonação e da respiração (o paciente precisa aprender a sincronizar a fonação com a deglutição do ar e não com a respiração como era anteriormente), 2- aquisição da capacidade de eructar voluntariamente, e 3- adaptação da palavra. A voz esofágica é recomendada devido a sua qualidade, inteligibilidade e naturalidade. Entretanto, há impeditivos para a emissão da voz esofágica e esses se classificam segundo a sua origem:

- de ordem física: fibrose da cicatriz cirúrgica, fístula tráqueo-cutânea, estenose do esôfago e problemas pulmonares;

- de ordem psicológica: vida solitária, problemas emocionais, falta de apoio familiar, falta de motivação e excesso de ansiedade.

Para os pacientes que são operados no Hospital das Clínicas, a voz esofágica tem sido o método de reabilitação vocal recomendado.

Quando o paciente não consegue a reabilitação vocal por esses métodos, resta-lhe comunicar-se com a voz bucal, mímica labial, escrita e gestos.

Considerando-se as características da pessoa com câncer de laringe, as conseqüências da cirurgia e o significado de ser laringectomizado, a assistência de enfermagem focalizando a comunicação, pode ser desenvolvida nos seguintes períodos cirúrgicos:

\section{- O periodo pré-operatório: O Medo}

A literatura de enfermagem cirúrgica retrata o período pré-operatório como sendo de ansiedade frente ao desconhecido, ao medo da cirurgia e da anestesia, do que pode acontecer. A redução da ansiedade é possível através do relacionamento empático, fornecendo-se as informações que o paciente requer para ter uma compreensão da sua doença e das conseqüências do procedimento cirúrgico. Estas devem ser adequadas ao seu interesse e necessidades, sem fantasias.

De um modo geral, alguns aspectos da vida do paciente precisam ser identificados como: características da personalidade do paciente, nível sócio-econômico e educacional, rede de apoio familiar e social, além da história da doença e condições fisiologicas. Serão esses dados que auxiliarão a predizer as dificuldades que o paciente poderá apresentar no pós-operatório. Na nossa experiência, o contato do paciente a ser operado com um outro laringectomizado, com boa qualidade de reabilitação tanto em nível da comunicação como dos outros aspectos, tem sido mais influente do que muitas palavras dos profissionais.

Considerando a afasia pós-operatória, é importante identificar as necessidades de comunicação do paciente e suas habilidades não verbais de expressão, como a comunicação corporal e, em particular, a gestual. Neste período, o paciente deve ser informado quanto às possibilidades de reabilitação vocal e assegurar-Ihe que a instituição dispõe do Serviço de Fonoaudiologia. Na visita do fonoaudiológo ao paciente, este profissional pode esclarecer as dúvidas e acrescentar informações pertinentes sobre o treinamento.

\section{- O pós-operatório: O grito silencioso}

Colocando-nos empaticamente com o paciente, esse é o período mais angustiante para ele. É quando ele se percebe incapaz de comunicar-se verbalmente com o meio ambiente e por isso, o grito silencioso. Devido ao esvaziamento ganglionar cervical, o paciente apresenta edema facial extenso que o impossibilita de movimentar os lábios. Por sua vez, a soroterapia impede-o de utilizar as mãos e, consequentemente, de escrever. Assim, a comunicação do paciente realiza-se pelo movimento palpebral, gestual dos dedos polegares e das expressões faciais. O enfermeiro precisa sensibilizarse e atentar para as possíveis mensagens não verbais do paciente ${ }^{3}$.

Após as primeiras 48 horas de pós-operatório, as condições fisiológicas do paciente começam a ser restabelecidas. A sua cognição e a sua necessidade de interagir com o meio ambiente acentuam-se. Nesse momento, pode-se utilizar a escrita, dependendo da habilidade do paciente. Para isso são necessários: papel de cor clara, caneta (e não lápis) e um apoio para o papel (prancheta). Esse material pode ser substituído pela lousa mágica. Esta, por ser um "brinquedo", pode não ser aceito pelo paciente, mas, é um recurso efetivo e de baixo custo. Na utilização da escrita, o receptor deve ser paciente e esperar que o paciente escreva a mensagem por inteiro; as interrupções e adivinhações pelo receptor, podem provocar ansiedade no paciente.

A maioria dos pacientes com os quais atuamos, utiliza a mímica labial exclusivamente para comunicar-se, nesse momento. É difícil compreender as mensagens pelos movimentos labiais. Há algumas estratégias que podem ajudar o enfermeiro: olhar nos olhos e lábios do paciente, solicitar-lhe para movimentar os lábios devagar e com amplitude, associando-se gestos e expressões faciais.

No preparo para a alta hospitalar, é importante identificarmos entre os familiares, aquele com o qual o paciente tem um bom relacionamento; ele será o centro de apoio social e 
portanto, deverá estar atento para as dificuldades da compreensão da comunicação pela mímica labial. Com o passar do tempo, esse indivíduo passa a ser "o porta voz" do paciente. É surpreendente a facilidade com que esses "porta voz" conseguem entender a mímica labial. A participação do fonoaudiólogo é importante para esclarecer o paciente e sua família sobre a reabilitação vocal. Os exercícios fonoarticulatórios facilitadores da voz esofágica (movimentos com os lábios, bochechas e língua) podem ser iniciados nesse momento e incentivados pela enfermagem. No nosso serviço, quando o paciente recebe a alta hospitalar ele deverá estar agendado para triagem no Setor de Fonoaudiologia.

\section{- O pós-alta hospitalar: As expectativas}

É no retorno ao convívio familiar e social que o paciente vivencia os estigmas relacionados à afonia e à alteração da imagem corporal.

$\mathrm{Na}$ ânsia de perceberem-se produzindo algum som, muitos pacientes desenvolvem a voz bucal ou a voz faríngea. A voz bucal utiliza a cavidade oral como reservatório de ar; essa voz produz sons de emissão rápida, formados por estalos de lábios, movimentos da mandíbula e língua contra o palato, denominados cliques bucais.

A voz faríngea utiliza a orofaringe como reservatório de ar; a língua, o palato mole e as paredes laterais e posterior da faringe atuam como vibradores. Embora apresente sons de características um pouco melhores que os da emissão bucal, a qualidade vocal resultante é áspera, estridente, de "pitch". Tanto a voz bucal como a faríngea produzem dificuldades para o desenvolvimento da voz esofágica. Assim, elas devem ser evitadas. Por esse motivo, o treinamento da voz esofágica deve ser iniciado precocemente ${ }^{2, ~}{ }^{\text {. }}$.

O treinamento da voz esofágica é realizado em grupo, entre 15 a 30 dias após a alta hospitalar. A média de tempo para que o paciente comece a produzir o som depende de cada um. O treinamento requer motivação, esforço e apoio. A participação no grupo de apoio pode ajudálo a superar as dificuldades. Nas reuniões grupais temos estimulado as pessoas que já utilizam a voz esofágica, a comentarem sobre as suas experiências. Com o mesmo objetivo temos incen tivado a participação dos familiares na realização dos exercícios.

A literatura relata que, em geral, os indivíduos que requeriam o uso da voz profissionalmente (cantores, radialistas, vendedores), antes da cirurgia, desenvolvem a voz esofágica mais rapidamente ${ }^{2,7,8}$. Um paciente que participava do grupo e que tinha a profissão de vendedor, conseguiu comunicar-se com a voz esofágica dez dias após o início do treinamento. Temos percebido e compartilhado dos esforços de alguns pacientes para o desenvolvimento da voz esofágica. O significado do "retornar a falar" está expresso no estudo de FLÁVIO; $\mathrm{ZAGO}^{4}$ em que o paciente apresenta-o "como se tivesse ganho na loteria". Após a aquisição da voz esofágica, os pacientes assumem uma atitude de "oradores" e a necessidade de exporem esse prêmio permeia os seus processos interativos, dando. lhe uma nova característica.

O prognóstico de desenvolvimento de uma fonação esofágica depende essencialmente de três fatores: controle da doença, alterações anatomofisiologicas decorrentes e ajustamento psicossocial do paciente.

De modo geral, BEHLAU; ZIEMER ${ }^{2}$ aceitam índices de 70 a $80 \%$ de sucesso no aprendizado da voz esofágica. Estudos recentes apontam uma diminuição dessa porcentagem, em virtude de fatores ligados à extensão da cirurgia e ao uso massivo de radioterapia no pós-operatório.

Seguramente, os fatores físicos (estenose do esôfago, fístulas faringoesofágicas, disfagia, problemas respiratórios) desempenham apenas um pequeno papel na média de $30 \%$ de insucesso na reabilitação vocal; são as características psicológicas dos indivíduos que têm revelado serem mais significativas ${ }^{2,7}$. Em relação a esse aspecto, ressaltamos a importância do grupo de apoio.

Para aqueles que desistem do treinamento, por problemas fisiologicos ou psicologicos, conforme mencionados anteriormente, existem as possibilidades de utilização da laringe eletrônica, da escrita, da mímica labial e da voz bucal ou faríngea.

\section{CONSIDERAÇÕES FINAIS}

Os avanços das técnicas cirúrgicas e as diferentes opções de reabilitação vocal têm aumentado as chances de sobrevida e de qualidade de vida dos pacientes.

As alternativas para a comunicação com a aquisição de uma nova voz, o aconselhamento individual e familiar e a reintegração social dos pacientes laringectomizados são as metas da sua reabilitação.

Não podemos subestimar o trauma emocional subsequente a uma laringectomia total; o paciente nunca se recupera totalmente dos efeitos da perda da voz laríngea, apenas aprende a conviver com essa nova situação de vida.

Os distúrbios emocionais vinculam-se também à inevitável mutilação física provocada pela cirurgia. A região da face e pescoço representa 
simbolicamente nosso aspecto social, crucial na formação da auto-imagem. Esta é a parte do corpo que não cobrimos com roupas, estando sempre à mostra. Qualquer tipo de alteração na imagem corporal nessa região acarreta profundos efeitos psicológicos, muitas vezes, maiores que os decorrentes de transformações em qualquer outra área do corpo humano ${ }^{3}$.

A reabilitação da pessoa laringectomizada não envolve apenas o aspecto vocal, mas, os outros aspectos da vida em sociedade. O GARPO. Laringectomizados tem procurado desenvolver o processo desde a internação hospitalar do paciente até o pós-alta, com a participação dos familiares e com a integração dos demais profissionais (enfermeiros, cirurgiões, assistente social, fonoaudióloga, nutricionista e outros).

Temos utilizado recursos educacionais para conscientizar os pacientes e seus familiares das dificuldades que podem enfrentar no dia a dia para buscar soluções possíveis. A seleção da escolha caberá a ele, dentro do seu contexto sócio-cultural, tendo o apoio de diferentes profissionais com os quais poderá compartilhar os seus sucessos e insucessos.

Para finalizar, acrescentamos que uma das grandes barreiras para a reabilitação dos laringectomizados é o estigma entre os profissionais de saúde. Segundo REDKO ${ }^{9,10}$, o câncer é tão estigmatizado que os profissionais de saúde e o paciente atribuem diferentes significados para a doença. Entre os profissionais, o paciente laringectomizado é muitas vezes rotulado como: difícil, alcoólatra, monstrinho, e outros. Esses estereótipos acabam determinando atitudes paternalistas e não de apoio. Consequentemente, essas atitudes desviam-se da compreensão de que a reabilitação é um direito individual.

\section{REFERÊNCIAS BIBLIOGRÁFICAS}

1 AITKEN-SWAN, J.; EASON, E.C. Reactions of cancer patientes on being told their diagnosis. Br. Med. J. v.21, p. 779-83. 1969

2 BEHLAU, M.S.; ZIEMER, R. Reabilitação foniátrica do laringectomizado. IN: BRANDÃO, L.G.; FERRAZ, A R. Cirurgia de cabeça e pescoço: princípios técnicos e terapeuticos. São Paulo, Roca. 1989. vol. 2. p. 371-83.

3 BLONDIS, M.N.; JACKSON, B.E. Nonverbal communication with patients: back to the human touch. 2. ed. New York, Wiley. 1982.

4 FLÁVIO, P.G.C.; ZAGO, M.M.F. "Como se tivesse ganho na loteria": o significado do retornando a falar pelo paciente laringectomizado. Trabalho apresentado no 5 Simpósio Brasileiro de Comunicação em Enfermagem (SIBRACEn), Ribeirão Preto-SP, 1996

5 KOWALSIKI, L.P. Câncer de cabeça e pescoço: estado atual e perspectivas futuras. Så Paulo. Âmb. Hosp., v.õ, n.59, p.13-25, 1994.

6 MAMEDE, R.C.M.; MOTONAGA, S.M.; MELLO FILHO, F.V Epidemiologia do câncer de cabeça e pescoço na região de Ribeirão Preto. Rev. Bras. Cir. Cabeç. Pesc. v.18, n.1, p. 29-32, 1994

7 OLIVEIRA, B.V.; OLIVEIRA, M.B.M. Reabilitação vocal. IN BRANDÃO, L.G.; FERRAZ, A R. Cirurgia de cabeça e pescoço : princípios técnicos e terapêuticos. São Paulo, Roca 1989. vol. 1. p. 413-20.

8 OTTO, S.E. Oncology nursing. St Louis, Mosby. 1991

9 REDKO, C.P. Representaçóes da doença dos pacientes com cancer de cabeça e pescoço. Acta Oncol. Bras. v. 14, n. 5 , p.231-7. 1994.

10 REDKO, C.P. Alguns estereótipos na relação dos profissionais de saúde com os pacientes de cancer de cabeça e pescoço. Acta Oncol. Bras. v. 15, n. 4, p.178-83. 1995.

11STEFFEN, N. Reabilitação vocal após laringectomia experiência pessoal. IN: BRANDÃO, L.G.; FERRAZ, A R. Cirurgia de cabeça e pescoço: princípios técnicos e terapêuticos. São Paulo, Roca. 1989. vol. 2. p. 355-69.

12 ZAGO, M.M.F. Plano de ensino para o preparo da alta médica do paciente laringectomizado. Ribeirão Preto. 1990. 145 p. Dissertação (Mestrado). Escola de Enfermagem de Ribeirão Preto, Universidade de São Paulo.

13 ZAGO, M.M.F.; STOPA, M.J.R.; MARTINEZ, E.L. Ser Laringectomizado. /Trabalho apresentado no 8 Seminário Nacional de Pesquisa em Enfermagem (SENPE), Ribeirão Preto-SP, 1995 